\title{
Senior care costs and demand will nearly double in the next decade
}

\author{
Cite as: CMAJ 2021 April 12;193:E526-7. doi: 10.1503/cmaj.1095932
}

Posted on cmajnews.com on March 26, 2021

anada isn't prepared to meet the growing challenges of caring for its ageing population, according to the Canadian Medical Association (CMA).

A report by Deloitte commissioned by CMA estimates that senior care costs and demand will nearly double by 2031. By that time, 606000 people will need long-term care, up 59.5\% from 2019. Meanwhile, the number of people requiring home care will increase $33 \%$ to 1.8 million.

The CMA projects this increase in demand will drive up the annual cost of senior care from $\$ 29.7$ billion in 2019 to $\$ 58.5$ billion in 2031 - amounting to $\$ 490.6$ billion in total expenditures over the next decade.

"Right now, we are not in any way able to meet that challenge," said CMA President Dr. Ann Collins. Moreover, Canada's governments do not appear to have plans for tackling the challenge.

According to Collins, the coronavirus disease 2019 pandemic has laid bare the fragility of Canada's senior care system, with long-term care residents accounting for $80 \%$ of deaths during the first wave. However, the pandemic also presents an opportunity for federal and provincial leaders to "stop bickering about jurisdictions to come together and devise a plan."

The CMA is calling on the federal government to develop a pan-Canadian elder care plan with the provinces and provide the provinces with additional, demographicbased funding to support that plan. "The provinces can't do it on their own," Collins said.

Provinces may be able to stretch current resources further by shifting more care from institutions to the community. For example,

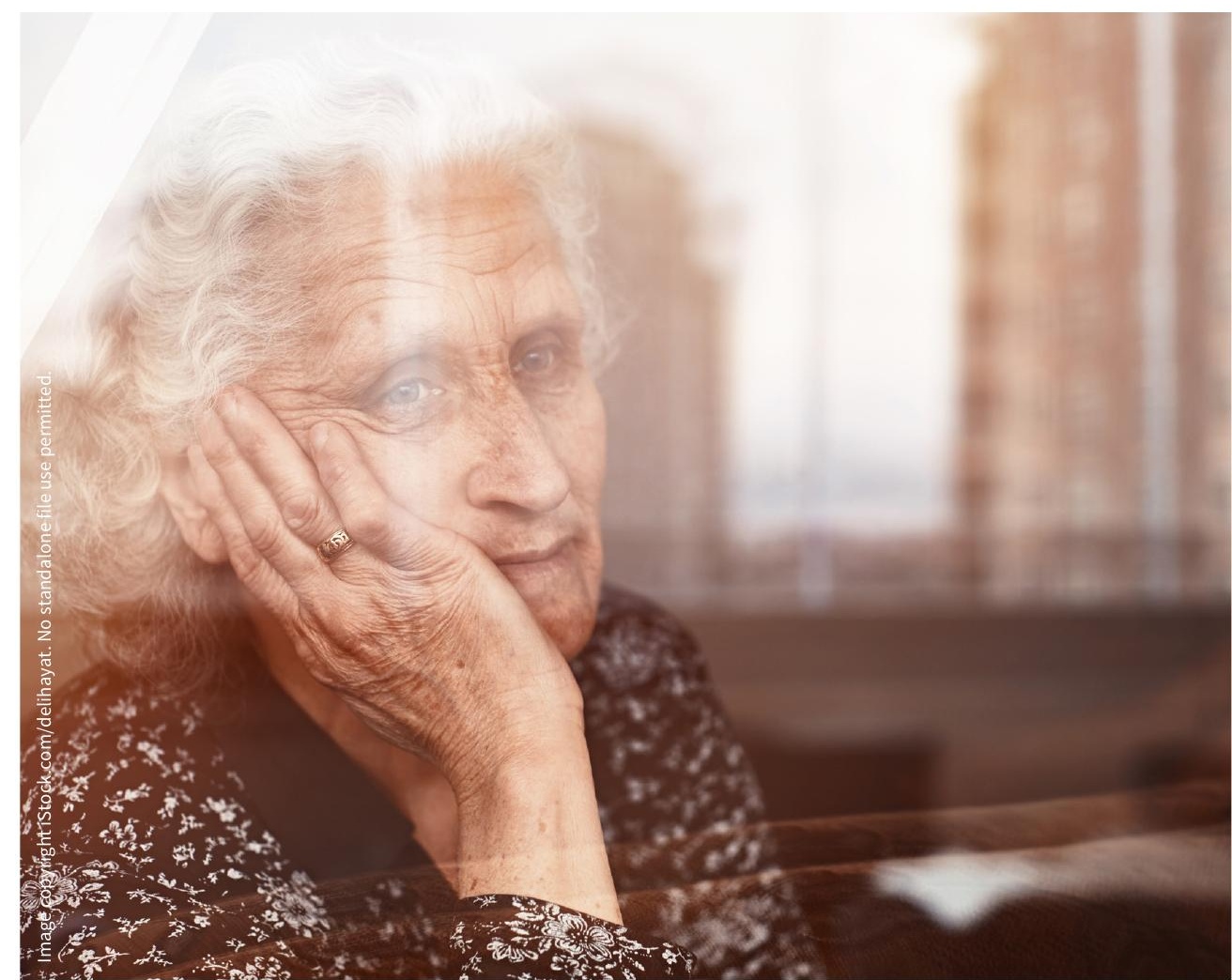

The pandemic has exposed the fragility of Canada's senior care systems, but also opportunities to strengthen them.

health systems could save $\$ 794$ million per year by diverting some 37000 people from long-term care to home care over the next decade. Moving patients who are waiting in hospital for long-term care to more appropriate community settings could save an additional $\$ 1.4$ billion per year by 2031.

But even with those measures, keeping up with the increasing demand for senior care will be "extremely expensive," Collins said. "We are beyond the point where tinkering around the edges will solve the problem."
In addition to a pan-Canadian plan, CMA is advocating for national standards and oversight of senior care. According to Collins, inconsistent standards "in staffing, in facilities, and facilities having regular inspections... contributed to the devastating effects of the pandemic in long-term care."

Other health advocates suggest that governments should re-evaluate the role of private, for-profit companies in senior care.

"Even before COVID, there were already major ongoing concerns for decades about understaffing, poor working conditions, 
lack of accountability and this patchwork system, which was infiltrated by private, for-profit corporations," says Dr. Amit Arya, a palliative care physician who works in long-term care facilities.

More than half of all long-term care homes in Canada are privately owned, and more than a quarter of those operate for-profit. "We pride ourselves on having universal health care... but that's not the care that's being provided for our seniors," says Arya. "It's a two-tier system, and it's been well established that private care results in poor quality care."

One recent CMAJ study of 623 Ontario long-term care homes found that for-profit facilities were linked to larger outbreaks of
COVID-19 and more resident deaths than non-profit facilities. Among the homes that experienced outbreaks, $6.5 \%$ of residents in privately owned, for-profit facilities died, compared to $5.5 \%$ of residents in private, non-profit homes and $1.7 \%$ in public facilities. Researchers attributed worse outcomes in for-profit homes to a "failure to upgrade and modernize facilities."

Public funding and delivery of senior care may also be more cost-efficient than Canada's current blend of public and private models, according to Vivian Stamatopoulos, who co-founded a group advocating for public senior care with Arya. One crosscountry comparison noted that large, forprofit nursing home chains tend to have high-profit margins and operating costs, the full extent of which may be underreported.

According to Stamatopoulos, failing to address the contributions of privatization to the costs and quality of senior care "will spell disaster in the years to come."

\section{Diana Duong, CMAJ}

Content licence: This is an Open Access article distributed in accordance with the terms of the Creative Commons Attribution (CC BY-NC-ND 4.0) licence, which permits use, distribution and reproduction in any medium, provided that the original publication is properly cited, the use is noncommercial (i.e., research or educational use), and no modifications or adaptations are made. See: https:// creativecommons.org/licenses/by-nc-nd/4.0/ 